\title{
Risk of False Positives during Sampling for Heterobasidion annosum s.l.
}

\author{
Anna Gunulf Åberg, Johanna Witzell, and Jonas Rönnberg, Swedish University of Agricultural Sciences, Southern Swedish Forest \\ Research Centre, SE-230 53 Alnarp, Sweden
}

\begin{abstract}
Gunulf Åberg, A., Witzell, J., and Rönnberg, J. 2016. Risk of false positives during sampling for Heterobasidion annosum s.l. Plant Dis. 100:175-179.

A standard method to detect infection by Heterobasidion annosum sensu lato (s.l.) in stumps or stems is to cut a disc and examine it under a microscope. Concerns have been raised that spores can be transferred from the bark to the cut surface, thus contaminating the sample. The aims of this study were to test whether viable basidiospores of $H$. annosum s.l. can be transferred from the bark onto disc surfaces by a chainsaw and to investigate the impacts of different sampling procedures on the extent of contaminations. Logs were cut with or without adding basidiospores to the bark prior to the cut. Infection measurements were significantly greater for discs with treated bark (100\% infected, infection coverage

$40 \mathrm{~cm}^{2} \mathrm{dm}^{-2}$ of disc area) compared with control discs (47\% infected, infection coverage 0.2 to $0.3 \mathrm{~cm}^{2} \mathrm{dm}^{-2}$ ). In addition, trees were sampled under authentic field conditions using different procedures. The infection measurements differed significantly depending on the procedure; sampling involving debarking or disinfection of the bark with $70 \%$ ethanol prior to cutting had lower measurements (6 to $19 \%$ and $13 \%$ infected, respectively) compared with leaving the bark on untreated (63 to $75 \%$ infected). Consideration of the contamination risk is warranted when evaluating the results of earlier studies and when planning new experiments.
\end{abstract}

The white-rot fungus Heterobasidion annosum (Fr.) Bref. sensu lato (s.l.) is one of the most economically and biologically important pathogens on conifer forest trees in the northern hemisphere (Woodward et al. 1998). The lifecycle of $H$. annosum s.l. starts with airborne basidiospores colonizing and germinating on freshly cut stumps or wounds (Isomäki and Kallio 1974; Rishbeth 1951a). The resulting mycelia can then grow into adjacent trees through root grafts and contacts (Rishbeth 1951b). After substantial mycelial colonization, basidiocarps typically form on the root or base of the tree, thus closing the lifecycle (Korhonen and Stenlid 1998).

Although noninvasive methods are emerging as an alternative to detect and visualize the internal decay in tree trunks and stumps, invasive sampling methods are still needed to assess the involvement of a single fungal species in the decay. To detect infection by $\mathrm{H}$. annosum s.l., it is possible to take a wood sample with an increment borer; however, because the borer only samples a small part of the stem surface, this method involves a risk of missing infections (Stenlid and Wästerlund 1986). Thus, many researchers sample by cutting a disc that is then incubated and investigated under a microscope, where $H$. annosum s.l. is recognized by the shape of its conidiophores (Garbelotto et al. 1999; Gonthier et al. 2002; Greig et al. 2001; Gunulf et al. 2013; Müller et al. 2007; Oliva et al. 2010; Redfern and MacAskill 2003; Rönnberg et al. 2013; Seaby and Schaible 2000; Swedjemark and Stenlid 1993; Tubby et al. 2008). However, Worrall and Harrington (1992) claim that cutting a disc entails a risk of basidiospores being dragged by the saw from the bark to the disc surface, where they then can germinate and form conidiophores, resulting in a risk of false positives in detection. If contaminations by basidiospores due to the sampling procedures are common, there is an urgent need to revise the sampling methods for detection of $H$. annosum s.l. infections in conifers. Thus far, however, this mechanism of contamination has never been systematically investigated and quantified.

Therefore, the aims of this study were to (i) test whether viable basidiospores can be transferred from the bark onto disc surfaces by a chainsaw, (ii) systematically investigate the impacts of different sampling procedures on the extent of contaminations, and (iii) suggest

Corresponding author: A. Gunulf Åberg; E-mail: Anna.Gunulf@slu.se

Accepted for publication 18 June 2015.

http://dx.doi.org/10.1094/PDIS-03-15-0269-RE

(C) 2016 The American Phytopathological Society improved invasive sampling methods for varying situations. The importance of the findings for practical forestry will be briefly discussed.

\section{Material and Methods}

Study design. The study was conducted in three experiments, each focusing on slightly different aspects of the aims above. The tree material used in all experiments was collected from a pure Norway spruce (Picea abies (L.) Karst.) stand with site index $36 \mathrm{~m}$ (dominant height at age 100 years) established in 1971 on former agricultural land at the estate of Trolleholm $\left(55^{\circ} 55^{\prime} \mathrm{N}, 13^{\circ} 17^{\prime} \mathrm{E}\right)$ in southern Sweden. The stand had undergone thinning before the study was initiated.

Transfer of basidiospores. The first experiment aimed at exploring whether basidiospores of $H$. annosum s.l. could be transferred from the bark of Norway spruce onto the disc surface when the disc was cut with a chainsaw. A log, approximately $1.5 \mathrm{~m}$ long, was cut with a chainsaw at least $2 \mathrm{~m}$ above any discoloration from 18 Norway spruce trees in June 2010. For practical reasons, the same trees were used in the third experiment and therefore had signs of H. annosum s.l. infection (i.e., discoloration or decay) at stump height. Before the cut, the bark in the area to be cut was removed and the exposed surface sanitized by spraying with $70 \%$ ethanol. A control disc was taken from each debarked and sprayed end of the logs to check for prior $H$. annosum s.l. infections. Infection was found in control discs from three logs; thus, the final number of logs used in the first experiment was 15 . Directly after control discs were collected, both ends of each log were sealed with plastic bags and then stored for 3 months at approximately $4^{\circ} \mathrm{C}$.

Basidiospores were collected on cellophane in petri dishes from basidiocarps growing on stumps in May and September 2010 by placing petri dishes under the basidiocarp and covering the whole stump with a plastic cover overnight. The May collection was done from basidiocarps growing on two Norway spruce stumps in the same stand where the tree material was collected. To increase the genetic variation of the spores, , in addition to the same stand, the September collection was also done in a mixed stand of Scots pine and larch $\left(55^{\circ} 55^{\prime} \mathrm{N}, 13^{\circ} 41^{\prime} \mathrm{E}\right)$ from eight stumps left from the previous rotation; however, determination of species was not possible for all stumps, although some could be distinguished as Norway spruce. Spore deposits were dried in room temperature for up to $24 \mathrm{~h}$, then stored in a fridge (approximately $4^{\circ} \mathrm{C}$ ) for 1 to 15 weeks before use. A spore suspension was mixed from the stored spore deposits the same day it was going to be used by shaking pieces of cellophane in distilled water. Five basidiocarps (four from the mixed stand collected in September and one from the Norway spruce stand collected 
in both May and September) had left visible deposits, which were used in the suspension. The concentration of the suspension was approximately $1.4 \times 10^{5}$ viable spores $/ \mathrm{ml}$, determined by a dilution series made on agar plates containing selective media (Kuhlman and Hendrix 1962).

The logs with diameters of approximately $10 \mathrm{~cm}$ were removed from cold storage in September 2010 and brought outdoors for the experiment. Each log was divided into three sections, which were randomly assigned to one of three treatments: control (cutting a disc from the log with a STIHL MS 200 chainsaw), mock inoculation (spraying an area of approximately $10 \mathrm{~cm}$ around the $\log$ with $9 \mathrm{ml}$ of distilled water prior to cutting a disc from that area), or inoculation (as in mock inoculation but spraying with $9 \mathrm{ml}$ of the basidiospore suspension of $H$. annosum s.l. described above). To minimize the risk of contaminations among treatments, the order in which treatments were applied was control, mock inoculation, and inoculation on every log. To check the viability of the spore suspension on wood media, extra discs that were sprayed with $2 \mathrm{ml}$ of the spore solution on each side were taken from five randomly selected sample logs. All discs were sealed in plastic bags directly after sampling and incubated for 7 days at room temperature (approximately $20^{\circ} \mathrm{C}$ ), after which they were examined using a dissecting microscope. Infection by $H$. annosum s.l. was detected by the presence of characteristic conidiophores (Greig 1998). Colonies on both sides of the sample discs were marked and counted and the total infected area assessed visually with an accuracy of $0.5 \mathrm{~cm}^{2}$ with the aid of a transparent grid. The location of colonies in the sapwood or heartwood was noted, and distinction between the two wood types was done by visual examination of color difference. Diameters of the discs were measured with a ruler to an accuracy of $0.5 \mathrm{~cm}$.

Contaminations depending on sampling procedure. The second experiment of the study aimed at evaluating the risk and extent of contaminations associated with different sampling procedures under field sampling conditions. The effects of debarking, sawing tools, exposure to aerial spore loads, and disinfection of trunk or disc were tested in 10 different combinations (Table 1) on 16 stumps. The stumps were created by felling Norway spruce trees in September 2009; only stumps without wood discoloration at stump height were included. To allow application of different sampling procedures on the same tree, stumps were left high, approximately $80 \mathrm{~cm}$ above ground. Debarking entailed removing all bark and cambium with a knife that was disinfected before the procedure by spraying the blade with $99 \%$ ethanol and igniting it. The sawing tools used were either a chainsaw (STIHL MS 200) or a large hand saw (Bahco bow saw, 759-mm blade), in which the blade was disinfected before each cut in the same manner as the knife. Three levels of exposure to aerial spore loads were tested: discs were either put in a plastic bag directly after being cut, held in the air for one extra minute before being put in a bag, or sawed indoors and put in a bag directly afterward. To enable indoor sawing, a piece of the trunk was taken indoors with the bark still on; the piece was approximately $30 \mathrm{~cm}$ long and was cut with a chainsaw and put in a plastic bag in the field. Disinfection of trunks was done prior to cutting a disc either by spraying the trunk surface or bark with $70 \%$ ethanol or spraying with $99 \%$ ethanol that was ignited. The discs were disinfected using the same approach as the trunks but the disc surface was sprayed. Sawdust was removed from each disc prior to being put in a plastic bag by gently tapping the side of the disc against the trunk of the stump. Each disc was approximately $2 \mathrm{~cm}$ thick.

For pragmatic reasons, the sampling order among procedures from top to bottom of each stump was the same for all stumps. In addition, one spore trap and one control to the spore trap were placed close to each stump for approximately $2 \mathrm{~h}$ during the sampling of the stumps in order to monitor the aerial spore loads during sampling. Spore traps and controls consisted of discs cut with a sterilized handsaw from the upper, debarked part of one of the felled trees. Each disc was put in a sterile petri dish immediately after cutting. The lid of the petri dishes to the spore traps were opened upon placement whereas the lids to the controls remained closed.

After an incubation period of 7 to 10 days at room temperature (approximately $20^{\circ} \mathrm{C}$ ), all discs were examined under a dissecting microscope. Infection by $H$. annosum s.l. was recognized by the presence of characteristic conidiophores (Greig 1998). Colonies on both sides of the sampled discs were marked and counted and the infected area of each colony was assessed visually to an accuracy of $0.5 \mathrm{~cm}^{2}$ with the aid of a transparent grid. Only the side facing up was examined on the spore traps and controls. The distance between the outer limit of each colony and the rim of the disc closest to the colony was measured to an accuracy of $1 \mathrm{~mm}$. Because some discs had bark and others did not, the width of the bark was not included in order to standardize the measurement. Diameter of each disc was measured perpendicularly with a ruler.

Development of sampling procedure. The third experiment was conducted after evaluating the result of the second experiment and the aim was to test whether a sampling procedure that gave no infections on the healthy trees in the second experiment could detect $H$. annosum s.l. in already infected and decayed trees. The sampling procedure in question was number 3 (i.e., to cut a disc from a trunk with the bark still on with a chainsaw and then disinfect the disc surface by spraying it with $70 \%$ ethanol; called disinfection hereafter). To test the procedure, 18 Norway spruce trees with decay or discoloration at stump height were felled in June 2010. In order to check that the discoloration or decay was caused by $H$. annosum s.l., the trunks were also sampled with a procedure deemed less likely to affect established infections while still having a low probability of contaminations. The procedure chosen was number 9 , debarking and disinfecting the trunk prior to the cut (called control hereafter). Along the trunk, three pairs of samples were taken. Each pair consisted of one disinfected disc and one control disc that was cut directly above. The paired discs were taken from different parts of the discolored

Table 1. Infection of wood discs by Heterobasidion annosum s.l. depending on sampling procedure ${ }^{\mathrm{y}}$

\begin{tabular}{lccc}
\hline Sampling procedure & Proportion infected discs & $\begin{array}{c}\text { Mean number of colonies per } \\
\text { exposed dm² disc area }\end{array}$ & $\begin{array}{c}\left.\text { Mean infected area } \mathbf{~ c m}^{2}\right) \text { per } \\
\text { exposed dm² disc area }\end{array}$ \\
\hline 1. Bark, chainsaw & $0.75 \mathrm{~A}$ & $1.69 \mathrm{~A}$ & $0.98 \mathrm{~A}$ \\
2. Bark, chainsaw, disc kept in air 1 min & $0.63 \mathrm{AB}$ & $1.17 \mathrm{~A}$ & $0.52 \mathrm{~B}$ \\
5. Bark, sterilized handsaw & $0.31 \mathrm{BC}$ & $0.28 \mathrm{~B}$ & $0.10 \mathrm{C}$ \\
8. No bark, chainsaw & $0.19 \mathrm{CD}$ & $0.12 \mathrm{BC}$ & $0 \mathrm{C}$ \\
6. Bark sprayed with 70\%, chainsaw & $0.13 \mathrm{CD}$ & $0.24 \mathrm{BC}$ & $0.18 \mathrm{C}$ \\
10. No bark, chainsaw, trunk sprayed and ignited & $0.13 \mathrm{CD}$ & $0.14 \mathrm{BC}$ & $0.01 \mathrm{C}$ \\
9. No bark, chainsaw, trunk sprayed with 70\% & $0.06 \mathrm{D}$ & $0.03 \mathrm{BC}$ & $0.02 \mathrm{C}$ \\
7. No bark, sterilized handsaw, trunk sprayed and & $0 \mathrm{D}$ & $0 \mathrm{BC}$ & $0 \mathrm{C}$ \\
$\quad$ ignited, sawed indoors & $0 \mathrm{D}$ & $0 \mathrm{C}$ & $0 \mathrm{C}$ \\
3. Bark, chainsaw, disc sprayed 70\% & $0 \mathrm{D}$ & $0 \mathrm{C}$ & $0 \mathrm{C}$ \\
4. Bark, chainsaw, disc sprayed and ignited & & \\
\hline
\end{tabular}

y Within each column, values that do not share a letter are significantly different from each other (Friedman's tests). The order of sampling was 1 to 10 on every stump.

${ }^{\mathrm{z}}$ Due to removal of three trees from the analysis of infected area. 
column within the trunk (ground, middle, and top) in order to capture the gradient of discoloration (heavy, medium, and light, respectively). After an incubation period of 7 to 10 days at room temperature, the discs were examined for conidiophore formation using a dissecting microscope. Supposing that established H. annosum s.l. might be affected by the ethanol on the surface of the discs, a longer incubation time was allowed for the disinfected discs. Thus, samples taken with the disinfection procedure were examined a second time after a total incubation period of 14 days if characteristic conidiophores for H. annosum s.l. could not be detected during the first examination. The total infected area on both sides was recorded. The diameter of the discs was measured perpendicularly with a ruler and the thickness of discs was measured with a ruler at two locations along the rim of the discs, in order to test whether disc thickness influenced the probability of finding conidiophores.

Calculation and statistics. The proportion of infected samples (depending on sampling procedure) was analyzed with Cochran's Q test using Friedman's test, with the trees as blocks for all parts of the study. Further pairwise comparisons were made with McNemar's test using Friedman's test.

Due to unequal variances and nonnormal residuals in all parts of the study, the number of colonies and the total infected area per exposed disc area, depending on treatment or sampling procedure, were analyzed with Friedman's test with trees as blocks. The data for each discoloration level were analyzed separately in the third experiment. Further pairwise comparisons between the data from different treatments were made with Friedman's test in the first experiment of the study. For the data from the second experiment, further pairwise comparisons were made, if the general Friedman test indicated significant differences between sampling procedures $(P \leq 0.05)$, by merging the procedures with similar medians in groups and expanding the groups stepwise until differences $(P \leq 0.05)$ were found. This was done to reduce the risk of mass significance. Due to missing values for total infected area per exposed disc area in the second experiment, three trees had to be removed from the analysis of that measurement.

The relationship between disc thickness and the probability of infection was analyzed using binary regression; each discoloration level within each sampling procedure was analyzed separately. Only datasets containing both infected and uninfected discs were used.

All statistical analyses were done in Minitab 16 (Minitab Inc., State College, PA

\section{Results}

Transfer of basidiospores. The proportion of infected discs differed depending on treatment of the bark prior to the cut $(P=$ $0.003)$, as did the number of colonies per exposed disc area $(P<$ $0.001)$ and infected area per exposed discs area $(P<0.001)$. Inoculation treatment significantly increased the values of all infection parameters compared with the mock inoculation and control treatments, while no difference was found between the mock inoculated and control discs (Table 2). The five extra discs that were sprayed with the basidiospore suspension after being cut were all infected with H. annosum s.l., with infection coverage of 65 to $90 \mathrm{~cm}^{2}$ per exposed disc square decimeter $\left(\mathrm{dm}^{2}\right)$, and the mean number of colonies per exposed disc area was 1.2 to 2.2 .

Of the 34 infected discs, $65 \%(n=22)$ had conidiophores of $H$. annosum s.l. solely in the sapwood, $32 \%(n=11)$ had conidiophores in both the sapwood and heartwood, and 3\% $(n=1)$ had conidiophores solely in the heartwood. The discs with infection in both the sapwood and heartwood were all from the inoculation treatment or extra discs that were sprayed with spores after being cut. Discs with infection solely in the sapwood were found in all treatments and the disc with infection in the heartwood was from the control treatment.

Contaminations depending on sampling procedure. The proportion of infected discs differed depending on sampling procedure in the field $(P<0.001)$, as did the number of colonies per exposed disc area $(P<0.001)$ and total infected area per exposed disc area $(P<0.001)$. Similar trends were found for all infection measurements (proportion infected discs, number of colonies, and total infected area per exposed disc area). The procedures where a chainsaw was used to cut a disc from a trunk with the bark still on (procedures 1 and 2) had the highest infection measurements while procedures involving removal of the bark prior to cutting a disc (procedures 7, 8, 9, and 10) had significantly lower values. Keeping the bark on but disinfecting it prior to the cut (procedure 6) also significantly reduced infection measurements compared with not treating the bark (procedure 1). The sawing tools used influenced infection; using a handsaw (procedure 5) instead of a chainsaw (procedure 1) significantly reduced infection measurements. Extended aerial exposure of the chainsaw cut discs (procedure 2) did not increase the infection measurements as compared with putting the disc directly in a plastic bag (procedure 1). Only three procedures resulted in no infections; those procedures entailed disinfection of the discs after the cut (procedures 3 and 4) or cutting the discs indoors with a handsaw from debarked and disinfected billets (procedure 7). The infection measurements of those three procedures were significantly lower compared with simply cutting a disc with a chainsaw (procedure 1) but they were not statistically different from samples taken with a chainsaw from disinfected trunks with or without bark (procedures 6, 9, and 10) (Table 1). Infection could only be located in 1 of the 16 spore traps; that infection consisted of one colony located on the rim of the disc, and measurements of colony expansion was not made. All control discs to the spore traps were uninfected.

The infections were generally located along the outer part of the discs. The outer border of all colonies in the second experiment started between 0 and $28 \mathrm{~mm}$ from the rim of the wood discs while the diameters of the infected discs ranged between 7.0 and $15.5 \mathrm{~cm}$. The sizes of the individual colonies were between 0.5 and $2 \mathrm{~cm}^{2}$ (mean $\left.=0.64 \mathrm{~cm}^{2}\right)$.

Development of sampling procedure. After 7 days of incubation, $H$. annosum s.l. was not found on any of the discs disinfected with $70 \%$ ethanol (procedure 3) taken from discolored or decayed trees. Most control discs cut from the same trees with a chainsaw after the trunk was debarked (procedure 9) were infected by $H$. annosum s.l. After 7 days of additional incubation time, one colony was found on one disinfected disc taken from the heavily discolored portion of the trunks. The proportion of infected samples and the total infected area were significantly higher for the control discs compared with the disinfected discs. For the heavily discolored wood, the proportions of infected discs were $6 \%$ for the disinfected discs compared with $100 \%$ for the control discs $(P<0.001)$, and the infected area was, on average, $0.007 \mathrm{~cm}^{2} / \mathrm{dm}^{2}$ on disinfected discs compared with $62.7 \mathrm{~cm}^{2}$ $(P<0.001)$ on control discs. The corresponding numbers for the medium discolored wood were $0 \%$ infected compared with $39 \%(P=0.008)$

Table 2. Heterobasidion annosum s.l. infection parameters for discs depending on inoculum treatment of the bark prior to the cut ${ }^{\mathrm{z}}$

\begin{tabular}{llccc}
\hline Treatment & $\boldsymbol{N}$ & Proportion of infected discs & $\begin{array}{c}\text { Mean number of colonies per exposed } \\
\mathbf{d m}^{2} \text { disc area }\end{array}$ & $\begin{array}{c}\text { Mean infected area }\left(\mathbf{c m}^{2}\right) \text { per exposed } \\
\mathbf{d m}^{\mathbf{2}} \mathbf{d i s c}_{\mathbf{a r e a}}\end{array}$ \\
\hline Spore inoculation & 15 & $1 \mathrm{~A}$ & $3.4 \mathrm{~A}$ & $40.4 \mathrm{~A}$ \\
Mock inoculation & 15 & $0.47 \mathrm{~B}$ & $0.5 \mathrm{~B}$ & $0.3 \mathrm{~B}$ \\
Control & 15 & $0.47 \mathrm{~B}$ & $0.3 \mathrm{~B}$ & $0.2 \mathrm{~B}$ \\
\hline
\end{tabular}

${ }^{\mathrm{z}}$ Spore inoculation entailed spraying with $9 \mathrm{ml}$ of basidiospore suspension $\left(1.4 \times 10^{5}\right.$ viable spores $\left./ \mathrm{ml}\right)$ and mock inoculation entailed spraying with $9 \mathrm{ml}$ of distilled water. Values within infection parameters with different letters are significantly different from each other (Friedman's test). 
and infected area $0 \mathrm{~cm}^{2}$ compared with $15.7 \mathrm{~cm}^{2}(P=0.008)$. None of the disinfected discs taken from the lightly discolored wood were infected compared with $50 \%$ of the control discs $(P=0.003)$, and infection covered $0 \mathrm{~cm}^{2}$ on the disinfected discs compared with $9.3 \mathrm{~cm}^{2}$ on the controls $(P=0.003)$.

On average, the thickness of discs was $28.3 \mathrm{~mm}$ (range: 17.5 to $40.0 \mathrm{~mm}$ ) for the disinfected discs and $20.3 \mathrm{~mm}$ (range: 10.0 to $30.5 \mathrm{~mm}$ ) for the control discs. There was no significant correlation between disc thickness and probability of infection.

\section{Discussion}

Our results demonstrate for the first time that, when cutting a disc from a Norway spruce log with a chainsaw, an increased amount of $H$. annosum s.l. basidiospores on the bark can lead to an increased amount of conidiophores on the disc surface. Due to the high amount of basidiospores sprayed on the bark during the experiment, our results cannot be directly extrapolated to the quantitative contamination risk during field sampling. However, evidence of the contamination risk also could be found on the samples taken under field conditions, and removing the bark prior to cutting a disc led to fewer conidiophores being detected compared with leaving the bark on. Thus, our findings provide support for the contamination mechanism suggested by Worrall and Harrington (1992), and emphasize that the risk of spore contaminations needs to be considered when trees and stumps are sampled using invasive methods for the purposes of scientific investigations.

The impact of contaminations due to sampling procedures will vary depending on the design of the experiment. If diseased trees are sampled and the experimental design links the presence of conidiophores to other signs of infection by H. annosum s.l., such as decay or discoloration (Greig 1998), the impact from contaminations will probably be small. However, if infection frequency during the early stages of infection, when discoloration has not yet occurred, is investigated, the impact from spore contaminations could be pronounced. In the present study, conidiophores were found on 63 to $75 \%$ of the discs taken with a chainsaw from healthy trunks in field conditions. Without other signs of infection, it could be difficult to discriminate between contaminations and established infections. Although the contaminations found after sampling in field conditions were generally small and located close to the rim of the discs, they could, in some cases, grow closer to the center, reaching areas up to $2 \mathrm{~cm}^{2}$. Furthermore, when extra spores were added to the bark surface before the cut, the contaminations got considerably larger and grew in both sapwood and heartwood. Thus, the results show that every $H$. annosum s.l. colony found in the heartwood of Norway spruce is not necessarily an established infection and, to complicate the interpretation, every colony found in the sapwood does not need to be a contamination. According to earlier studies, a considerable proportion of spore infections established in Norway spruce stumps are found in sapwood (Oliva et al. 2013) and, even though infections in trees typically reside within the heartwood, they are known to grow also in the sapwood (Stenlid and Redfern 1998). A possible approach to distinguish between established mycelia and contaminations could be to only consider infections resulting in conidiophores appearing identically on both sides of the discs. Although this approach seems logical, a thorough investigation of the appearance of conidiophores of both true infections and contaminations needs be undertaken to make it evidence based. Until then, researchers investigating $H$. annosum s.l. infections that are not linked to signs other than conidiophores need to particularly consider the risk of contaminations and adjust the sampling procedures accordingly. Considering that sampling by simply cutting a disc with a chainsaw has been a common procedure used by many researchers, it seems prudent to also carefully consider the risk of contaminations when evaluating earlier literature.

When infections on sound-looking wood are investigated, the sampling procedure used should generate a minimum of contaminations. Of the procedures tested in the present study, only samples where the bark was removed prior to cutting and the trunk disinfected or where the disc surface was sprayed with ethanol after the cut were free of conidiophores (Table 1). Because spraying the disc appears to also kill off established infections in decayed logs, the safest way to sample is probably to debark the stump or stem and then to spray and ignite the trunk with ethanol prior to the cut indoors. However, a significant reduction of contamination, compared with simply cutting a disc with a chainsaw, was also achieved by spraying the bark with ethanol prior to the cut or by using a sterilized handsaw instead of a chainsaw (Table 1). In fact, no statistical difference regarding infection parameters could be detected between the procedures where bark was removed and where the bark was simply sprayed. Thus, if debarking is deemed too laborious, a feasible option could be to spray the bark with $70 \%$ ethanol prior to the cut. However, because some of the discolored discs taken from trunks sprayed with ethanol prior to the cut were without conidia, it would be desirable to test this procedure further on decayed wood to evaluate whether established infections are affected by ethanol being dragged by the saw from the bark onto the disc surface.

Surface disinfection of discs with $70 \%$ ethanol after the cut appeared to kill established infections and, therefore, is not recommended. Other procedures for cleaning samples have been used by different researchers: discs have been washed with water (Morrison and Redfern 1994; Oliva et al. 2013) and wood pieces have been flamed (Lygis et al. 2004; Swedjemark and Stenlid 1993) or dipped in alcohol and immersed in a solution of calcium hypochlorite (Rishbeth 1950). It would be interesting to develop and test these and other procedures on both uninfected and decayed wood to obtain a reliable sampling procedure involving surface disinfection because that would allow fast and easy sampling in the field with a chainsaw.

Because adding spores to the bark prior to cutting the disc increased both the infection frequency and the extent of the area occupied by conidiophores, the impact of contaminations will also vary depending on the amount of spores on the bark. Several environmental factors that affect spore release, deposition, and survival could influence spore abundance on the bark. The two most important factors are probably temperature and humidity (Redfern and Stenlid 1998). Spores are released when temperatures in the basidiocarp exceeds $0^{\circ} \mathrm{C}$ (Meredith 1959) and spore depositions are then positively correlated with temperature, at least up until $22^{\circ} \mathrm{C}$ (Haraldstad 1962). Spore deposition ceases when the maximum temperatures on the site approaches $32^{\circ} \mathrm{C}$ (Ross 1973). Air humidity will also influence spore release; Rishbeth (1951a) found that spore production slowed down or even ceased during dry periods. Thus, it is likely that the risk of contaminations will be high during and following periods of mild and humid weather and, considering the positive impact of proximity to basidiocarps on spore deposition (Kallio 1970), on sites located close to disease centers. Although few spores are expected to be released during extremely cold, warm, or dry weather, the risk of contaminations should still be considered even if $H$. annosum s.l. is absent from the air. In the present study, spore deposition was low during sampling; only one small colony was found on the spore traps, while contaminations where common. Basidiospores of $H$. annosum s.l. are reported to remain viable for at least 16 months in favorable settings (Rishbeth 1959). Although exposure to daylight and high temperatures have a negative impact on spore viability (Rishbeth 1951a), it is likely that spores can survive several months on the bark during the winter (Shaw 1981). Thus, the risk of spores being dragged from the bark during the cut and then germinating on the disc surface during incubation needs to be considered even if sampling is conducted in a setting unfavorable to spore deposition.

Our results may also have implications for forestry practices. The process of spores being dragged from the bark during a cut could result in primary infection of stumps during harvesting. During periods with low or no spore deposition, stumps could still get infected by spores dragged from the bark when the tree is felled. If the bark acts as a reservoir of spores, the poor correlation between spore availability in the air and stump infection (Driver and Ginns 1969; Stambaugh et al. 1962) could be explained. The impact on practical forestry would depend on the size of the reservoir as well as on whether the environmental requirements of spore germination differ noticeably from those of spore deposition. Although the bark reservoir size 
is potentially a sufficient source of primary infection during periods without spore deposition, given that the majority of discs got infected when cut with a chainsaw in the present study (Table 1), more detailed information about requirements for spore deposition and germination is needed before we can elucidate the practical implications of that reservoir.

In conclusion, our results confirm that basidiospores can be dragged from the bark onto disc surfaces by a chainsaw, leading to a considerable risk of spores contaminating samples taken during scientific investigations of $H$. annosum s.l. infections. The impact from such contaminations could be pronounced, in particular when the investigated infection is not linked to signs of infection other than the presence of conidiophores. The risk of contaminations can be reduced by sampling with a handsaw; by spraying the bark with ethanol prior to the cut; or by debarking, spraying, and igniting the trunk with ethanol prior to the cut.

\section{Acknowledgments}

This study was financially supported by the research program Future Forests, Anna och Nils Håkanssons stiftelse, Stiftelsen Nils och Dorthi Troëdssons forskningsfond, and Stiftelsen Rattsjös skogsvårdsfond. We thank J.-E. Englund for statistical consultation, M. Cleary for language revision, G. MacAskill and J. Pratt for advice on basidiospore collection and handling, and the estate of Trolleholm for providing spruce trees.

\section{Literature Cited}

Driver, C. H., and Ginns, J. H. 1969. Ecology of slash pine stumps: Fungal colonization and infection by Fomes annosus. For. Sci. 15:2-10

Garbelotto, M., Cobb, F., Bruns, T. D., Otrosina, W., Popenuck, T., and Slaughter, G. 1999. Genetic structure of Heterobasidion annosum in white fir mortality centers in California. Phytopathology 89:546-554.

Gonthier, P., Garbelotto, M., and Nicolotti, G. 2002. European pines may be simultaneously infected by more than one species of Heterobasidion. Plant Dis. $86: 814$

Greig, B. J. W. 1998. Field recognition and diagnosis. Pages $34-42$ in: Heterobasidion annosum: Biology, Ecology, Impact and Control. S. Woodward, J. Stenlid, R. Karjalainen, and A. Hütterman, eds. CAB International, Wallingford, UK.

Greig, B. J. W., Gibbs, J. N., and Pratt, J. E. 2001. Experiments on the susceptibility of conifers to Heterobasidion annosum in Great Britain. For. Pathol. 31:219-228.

Gunulf, A., Wang, L. Y., Englund, J.-E., and Rönnberg, J. 2013. Secondary spread of Heterobasidion parviporum from small Norway spruce stumps to adjacent trees. For. Ecol. Manage. 287:1-8.

Haraldstad, A. 1962. Investigations on Fomes annosus in Høylands-komplekset, south-western Norway. Nytt Mag. Bot. 9:175-198.

Isomäki, A., and Kallio, T. 1974. Consequences of injury caused by timber harvesting machines on the growth and decay of spruce (Picea abies (L.) Karst.). Acta For. Fenn. 136:1-25.

Kallio, T. 1970. Aerial distribution of the root-rot fungus Fomes annosus (Fr.) Cooke in Finland. Acta For. Fenn. 107:1-55.

Korhonen, K., and Stenlid, J. 1998. Biology of Heterobasidion annosum. Pages 43-70 in: Heterobasidion annosum: Biology, Ecology, Impact and Control. S. Woodward, J. Stenlid, R. Karjalainen, and A. Hütterman, eds. CAB International, Wallingford, UK.

Kuhlman, G., and Hendrix, F. 1962. A selective medium for the isolation of Fomes annosus. Phytopathology 52:1310-1311.

Lygis, V., Vasiliauskas, R., Stenlid, J., and Vasiliauskas, A. 2004. Silvicultural and pathological evaluation of Scots pine afforestations mixed with deciduous trees to reduce the infections by Heterobasidion annosum s.s. For. Ecol. Manage. 201:275-285.
Meredith, D. S. 1959. The infection of pine stumps by Fomes annosus and other fungi. Ann. Bot. (London) 23:455-476.

Morrison, D. J., and Redfern, D. B. 1994. Long-term development of Heterobasidion annosum in basidiospore-infected Sitka spruce stumps. Plant Pathol. 43:897-906.

Müller, M. M., Heinonen, J., and Korhonen, K. 2007. Occurrence of Heterobasidion basidiocarps on cull pieces of Norway spruce left on cutting areas and in mature spruce stands. For. Pathol. 37:374-386.

Oliva, J., Bernat, M., and Stenlid, J. 2013. Heartwood stump colonisation by Heterobasidion parviporum and H. annosum s.s. in Norway spruce (Picea abies) stands. For. Ecol. Manage. 295:1-10.

Oliva, J., Thor, M., and Stenlid, J. 2010. Long term effect of mechanical stump treatment against Heterobasidion annosum root rot in Picea abies. Can. J. For. Res. 40:1020-1033.

Redfern, D. B., and MacAskill, G. A. 2003. Susceptibility of Sitka spruce and grand fir trees to decay by Heterobasidion annosum. For. Pathol. 33:39-52.

Redfern, D. B., and Stenlid, J. 1998. Spore dispersal and infection. Pages 105-124 in: Heterobasidion annosum: Biology, Ecology, Impact and Control. S. Woodward, J. Stenlid, R. Karjalainen, and A. Hütterman, eds. CAB International, Wallingford, UK.

Rishbeth, J. 1950. Observations on the biology of Fomes annosus, with particular reference to East Anglian pine plantations. I. The outbreaks of disease and ecological status of the fungus. Ann. Bot. (London) 55:365-383.

Rishbeth, J. 1951a. Observations on the biology of Fomes annosus, with particular reference to East Anglian pine plantations. II. Spore production, stump infection, and saprophytic activity in stumps. Ann. Bot. (London) 15:1-21.

Rishbeth, J. 1951b. Observation on the biology of Fomes annosus, with particular reference to East Anglian pine plantations. III. Natural and experimental infection of pines, and some factors affecting severity of the disease. Ann. Bot. (London) 15:221-246.

Rishbeth, J. 1959. Dispersal of Fomes annosus Fr. and Peniophora gigantea (Fr.) Massee. Trans. Br. Mycol. Soc. 42:243-260.

Rönnberg, J., Berglund, M., Johansson, U., and Cleary, M. 2013. Incidence of Heterobasidion spp. following different thinning regimes in Norway spruce in southern Sweden. For. Ecol. Manage. 289:409-415.

Ross, E. W. 1973. Fomes annosus in the southeastern United States: Relation of environmental and biotic factors to stump colonization and losses in the residual stand. Tech. Bull. 1459. United States Department of Agriculture Forest Service, Washington, DC.

Seaby, D. A., and Schaible, R. C. 2000. Preventing Heterobasidion annosum from colonizing chemically thinned Sitka spruce stems. Forestry 73:351-359.

Shaw, C. G. 1981. Basidiospores of Armillaria mellea survive an Alaskan winter on tree bark. Plant Dis. 65:972-974.

Stambaugh, W. J., Cobb, F. W., Schmidt, R. A., and Krieger, F. C. 1962. Seasonal inoculum dispersal and white pine stump invasion by Fomes annosus. Plant Dis. Rep. 46:194-198.

Stenlid, J., and Redfern, D. B. 1998. Spread within the tree and stand. Pages 125-142 in: Heterobasidion annosum: Biology, Ecology, Impact and Control. S. Woodward, J. Stenlid, R. Karjalainen, and A. Hütterman, eds. CAB International, Wallingford, UK.

Stenlid, J., and Wästerlund, I. 1986. Estimating the frequency of stem rot in Picea abies using an increment borer. Scand. J. For. Res. 1:303-308.

Swedjemark, G., and Stenlid, J. 1993. Population dynamics of the root rot fungus Heterobasidion annosum following thinning of Picea abies. Oikos 66:247-254.

Tubby, K. V., Scott, D., and Webber, J. F. 2008. Relationship between stump treatment coverage using the biological control product PG Suspension, and control of Heterobasidion annosum on Corsican pine, Pinus nigra ssp. laricio. For. Pathol. 38:37-46.

Woodward, S., Stenlid, J., Karjalainen, R., and Hüttermann, A. 1998. Heterobasidion annosum: Biology, Ecology, Impact and Control. CAB International, Cambridge, UK.

Worrall, J. J., and Harrington, T. C. 1992. Heterobasidion. Pages 86-90 in: Methods for Research on Soilborne Phytopathogenic Fungi. L. L. Singleton, J. D. Mihail, and C. M. Rush, eds. American Phytopathological Society, St. Paul. 